University of Nebraska - Lincoln

DigitalCommons@University of Nebraska - Lincoln

Faculty Publications, Department of Psychology

Psychology, Department of

6-2009

\title{
Food exemplar salience: What foods do people think of when you tell them to change their diet?
}

\author{
Carolyn R. Brown-Kramer \\ University of Nebraska-Lincoln, cbrownkramer2@unl.edu \\ Marc T. Kiviniemi \\ SUNYBuffalo, mtk8@buffalo.edu \\ Julie A. Winseman \\ University of Nebraska-Lincoln
}

Follow this and additional works at: https://digitalcommons.unl.edu/psychfacpub

Part of the Psychiatry and Psychology Commons

Brown-Kramer, Carolyn R.; Kiviniemi, Marc T.; and Winseman, Julie A., "Food exemplar salience: What foods do people think of when you tell them to change their diet?" (2009). Faculty Publications, Department of Psychology. 475.

https://digitalcommons.unl.edu/psychfacpub/475

This Article is brought to you for free and open access by the Psychology, Department of at DigitalCommons@University of Nebraska - Lincoln. It has been accepted for inclusion in Faculty Publications, Department of Psychology by an authorized administrator of DigitalCommons@University of Nebraska - Lincoln. 


\title{
Food exemplar salience: What foods do people think of when you tell them to change their diet?
}

\author{
Carolyn R. Brown-Kramer, ${ }^{\text {a Marc T. Kiviniemi, }}$, and Julie A. Winseman ${ }^{\mathrm{a}}$ \\ a University of Nebraska-Lincoln, Lincoln, NE, USA \\ b University at Buffalo, 314 Kimball Tower, 3435 Main Street, Buffalo, NY 14214, USA \\ Corresponding author - M. T. Kiviniemi, email $\underline{\text { mtk8@buffalo.edu }}$
}

\begin{abstract}
Understanding which specific foods easily come to mind when individuals consider categories of dietary behavior may help explain observed patterns of dietary intake. We examined which specific behavioral exemplars are most easily retrieved from memory when individuals consider broad dietary categories. Participants reported specific foods that come to mind when considering high fat foods, low fat foods, and fruits/vegetables. Salient foods differed from those suggested in dietary guidelines, were distinct from those known to be major diet components, and showed a non-trivial number of incorrect responses. These findings have implications for understanding how individuals respond to dietary guidelines and devising effective intervention strategies.
\end{abstract}

Keywords: Accessibility of food choices in memory, nutrition, diet

Dietary choices contribute to many pressing public health problems (Mokdad et al., 2004). Many public health interventions provide dietary change messages (e.g., Havas et al., 1995), but there is still a disparity between current consumption patterns and recommended dietary practices (Bachman et al., 2008; Guenther et al., 2006; United States Department of Health and Human Services, 2005).

There may be an important disconnect between the level of specificity at which public health messages are targeted versus the level at which individuals actually make decisions about dietary behaviors. Consider a person who takes to heart a public health message to eat more fruits and vegetables. Although her goal can be articulated at the broad category level of fruits and vegetables, actually implementing the relevant behavior change requires thinking about more specific food choices that belong to the category (e.g., I will buy carrots; I will eat spinach).

This difference in level of specificity between messages about global behavior categories and regulation of specific dietary choices raises an important issue for understanding individuals' behavioral decision making. For most dietary behaviors, there are a large number of specific food items that are part of a given category (e.g., vegetables includes at least 71 different specific food items; Achterberg et al., 1994). It is highly unlikely that the person will (or even could) consider the entire range of possible specific behavioral options each time a dietary choice is made. In situations such as this where a general category of potential behaviors must be implemented at the more concrete level and where a large number of potential concrete-level behavioral options exists, an important step in the behavioral decision making process is generating potential choice options from the category (Laroche \& Brisoux, 1989).

This situation has been extensively examined by researchers in the area of consumer behavior. Several models of such behavior assume that choices (e.g., which particular brand of a product to buy) are made based on an "evoked set" of potential behavioral choices (see Church et al., 1985, for an overview of these models). The evoked set consists of those options that are brought to mind and actively considered when making a behavioral choice; other potential behavioral options, which are not brought to mind, are not actively considered. Only those potential behavioral options which are brought to mind are considered and it is therefore considered highly unlikely that an unevoked behavioral option will be selected and enacted (Laroche \& Brisoux, 1989).

Thus, an important question for understanding behavior choice is this: when individuals are told to eat more fruits and vegetables or to lower their intake of high fat foods, what specific foods are they most immediately bringing to mind and thus considering as behavioral options? This question of which items are most easily retrieved has substantial relevance. In other domains, it has been shown that when considering behavioral options, those options that are most readily brought to mind are most likely to be enacted.

Given that broad category public health recommendations about diet must be enacted in terms of specific behavioral choices, that the possible number of choices are larger 
than an individual can realistically consider at a given moment of choice, and the evidence from other domains that items that are brought to mind most quickly and readily are most likely to guide behavior, it is important to know what specific food items are most readily brought to mind when individuals are asked to think about categories of dietary behaviors. Such an examination may aid our understanding of why there might be a lack of variability in individuals' diets and difficulty in complying with nutritional recommendations about sub-categories of foods (Guenther et al., 2006). For example, if individuals who are told to eat more fruits and vegetables immediately think only of apples, bananas, and carrots, it is unlikely that they will spontaneously form an intention to eat more green leafy vegetables.

A number of studies have examined what individuals interpret as being meant by general food categories such as healthy and unhealthy (Croll et al., 2001; Povey et al., 1998), diet foods (Sobal \& Cassidy, 1987, 1990), and specific ingredients (e.g., whole grain, high fiber; Marquart et al., 2006; Sobal \& Cassidy, 1993). Other studies have examined how participants categorize specific food items (Blake et al., 2007; Ross \& Murphy, 1999). However, to our knowledge no study has examined what types of specific food items are brought to mind most quickly and easily when individuals consider the categories of foods often mentioned in educational recommendations.

In this cross-sectional questionnaire study, we sought to provide an initial answer to this question by examining what specific food exemplars were particularly salient to young adults when they were asked to think about three common food categories: fruits and vegetables, high fat foods, and low fat foods. For each category, participants were asked to report the first three foods that came to mind when they thought about each category. Limiting the number of foods to three captures the salience/ease of recall of specific foods (as opposed to an extensive search in memory for any food item); such response listings have been shown to be a valid measure of accessibility of items in memory (Fazio et al., 2000; Posavac et al., 1997) and have been used to assess food categorization in past studies (e.g., Sobal \& Cassidy, 1987). Participants' responses were coded and categorized to examine what sorts of foods participants found most salient, how those salient foods compared to dietary guidelines, and how the salient foods compared to epidemiological data on common sources of dietary intake.

\section{Method}

Three hundred sixteen participants from a large Midwestern university (76 men, 240 women; average age 20.0 years; $85.4 \%$ Caucasian) took part in the study in exchange for course extra credit. All participants were students in psychology courses; students came from a variety of majors. Mean body mass index (BMI) was 23.1 (S.D. $=4.1)$; 156 participants $(49.4 \%$ total; of these, $18.6 \%$ were men and $81.4 \%$ were women) reported that they were trying to lose weight at the time of the study.

The study protocol was approved by the university Institutional Review Board. Participants completed the study in small groups of 3-10 people. Participants completed a short demographic form (gender, age, ethnicity, weight, and height). They responded to question prompts for each category (fruits and vegetables, high fat foods, low fat foods). For each, they were asked to write down the first 3 foods that came to mind when considering the category (e.g., "When you think about fruits and vegetables, what are the first 3 foods that come to mind?"). These items were included within a larger questionnaire about people's thoughts and feelings about common health behaviors. Participants completed the questionnaire at their own pace and were given an educational debriefing when they were finished.
To allow examination of the foods participants generated within each category and their relation to dietary guidelines and other factors, we created a categorization/classification scheme for each type of food. For fruit/vegetable consumption, each response was categorized based on types of fruits and vegetables discussed in the USDHHS Dietary Guidelines for Americans (2005); subtypes included orange vegetables, dark green vegetables, starchy vegetables, lettuce, beans, other vegetables, mixed fruits, yellow fruits, berries, and green fruits. For example, a response of "blueberry" was coded as part of the berry category, and a response of "spinach" was classified in the dark green vegetable category. Because recommendations for high and low fat foods are not broken down into similar subcategories, the coauthor with formal training in nutrition (JW) classified responses to the high fat food prompt into 3 categories: high in fat (e.g., French fries), sometimes high in fat (e.g., pasta, which can be high in fat if tossed with butter or low in fat if prepared with tomato paste), or low in fat (i.e., an incorrect response that lists a food that is actually low in fat, such as sugar). The same was done for categorizing responses to the low fat prompt into low in fat, sometimes low in fat, and high in fat categories. The categorization was reviewed by all authors; disagreements were resolved through discussion.

\section{Results}

\section{Descriptive analysis}

Participants generated 45 different fruits/vegetables, 66 different high fat foods, and 70 different low fat foods in response to the prompts. Responses listed by at least $5 \%$ of participants are shown in Table 1. As can be seen in Table 1, the variety of different foods listed differs by food type. For fruits and vegetables, nearly $50 \%$ of responses were one of four foods (apple, carrot, banana, orange), whereas for high fat foods and low fat foods, nearly twice as many foods (7 different foods for each) were listed within the top $50 \%$ of responses (for high fat foods: French fries, hamburger, potato chips, pizza, chocolate, ice cream, candy; for low fat foods: yogurt, fruit, salad, vegetables, apple, carrot, cereal).

\section{Fruits and vegetables: salient items relative to dietary guidelines}

There are several interesting things to note regarding the salience of certain vegetables, as indicated by responses to the fruits and vegetables prompt. Orange vegetables (e.g., carrots, squash, yams) comprised $34.8 \%$ of all vegetable responses (carrots accounted for the vast majority of these responses), although dietary guidelines recommend that orange vegetables comprise only $11.4 \%$ of one's total vegetable intake. In contrast, legumes comprised less than $1 \%$ of all vegetable responses, although they should comprise $17.1 \%$ of one's vegetable intake. There are substantial differences across vegetables categories in salience, and relative salience is not proportional to recommended dietary intake.

Participants listed a disproportionately large number of fruits in response to the fruits and vegetables prompt. Dietary guidelines suggest that individuals on a 2000-calorie per day diet should eat 2 cups of fruits and 2.5 cups of vegetables per day (i.e., roughly equivalent, with slightly more vegetables). Participants listed many more fruits $(531 ; 56.2 \%)$ and many fewer vegetables $(322 ; 34.1 \%$; the remaining $9.7 \%$ of responses were extraneous; e.g., "healthy"); again, salience is not proportional to recommended dietary intakes (e.g., if participants followed dietary guidelines in listing foods in the fruits and vegetables food type, they should have listed 420 fruits: $44.4 \%$ and 525 vegetables: $55.6 \%$ ). 
Table 1. Foods listed by at least $5 \%$ of participants, including food category, response, response frequency, and percentage of the corresponding category comprised of that response.

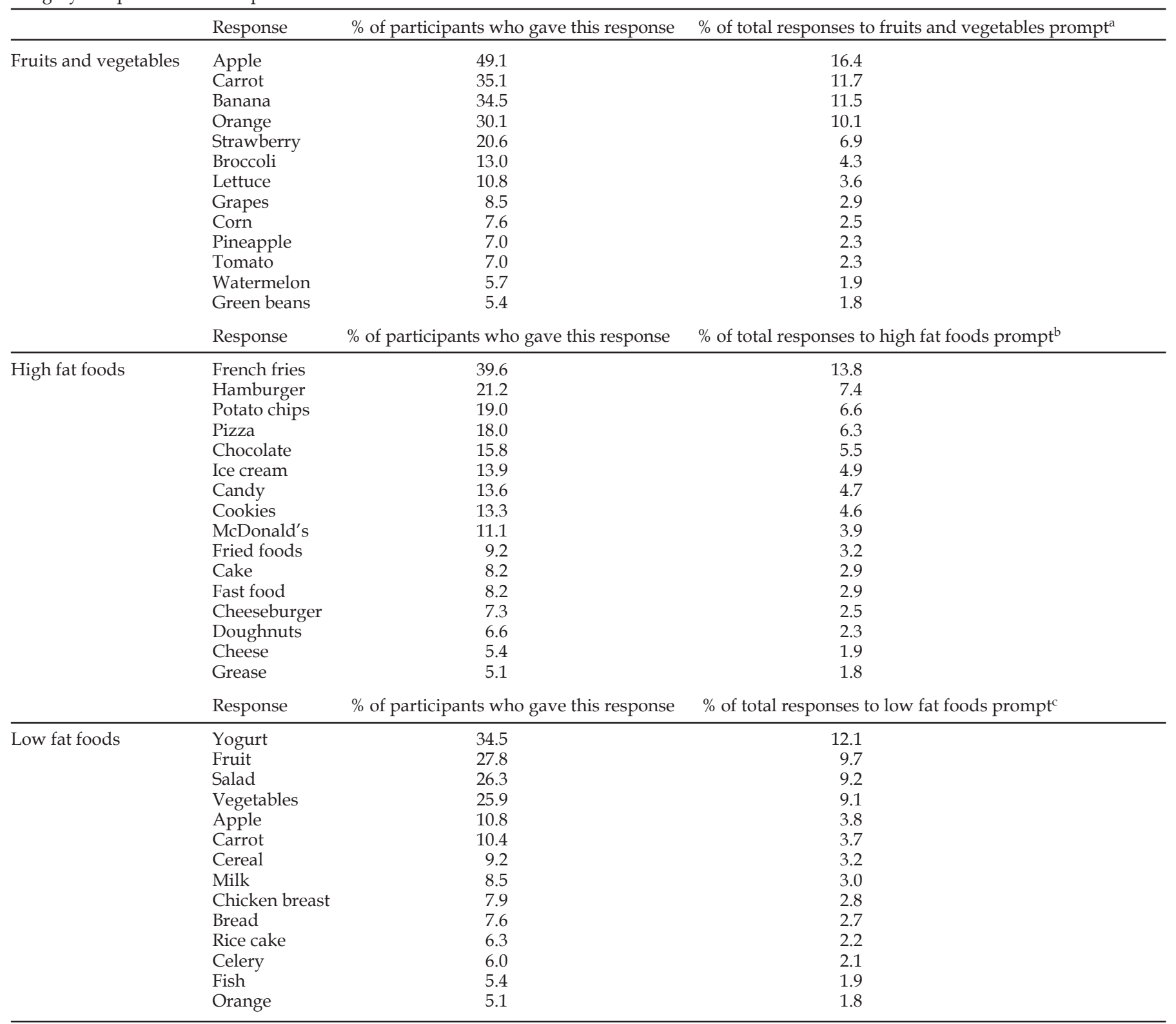

\footnotetext{
a Total number of responses to the fruits and vegetables prompt $=945$.

$\mathrm{b}$ Total number of responses to the high fat foods prompt $=908$.

${ }^{c}$ Total number of responses to the low fat foods prompt $=904$.
}

\section{Response errors in foods listed}

There were a small but interesting set of errors in participants' responses to the high fat foods prompt. For the high fat foods prompt, participants listed foods that are actually low in fat (e.g., soda, sugar, carbohydrates, bread, potato, and bagel) 27 times out of 906 total responses (3.0\%).

\section{Sources of total dietary fat}

Responses to the high fat foods prompt were unrepresentative of the main sources of fats in the American diet (Cotton et al., 2004). For instance, participants listed beef and potato chips at high rates $(16.3 \%$ and $6.6 \%$, respectively) and cheese and milk at low rates $(1.9 \%$ and $0.3 \%$, respectively) in response to the high fat food prompt. Relative to sources of total fat in the average American diet, beef and potato chips had disproportionally high salience (beef actually comprises only $10.1 \%$ of total fat intake and potato chips 3.9\%) and cheese and milk had disproportionally low salience (cheese actually comprises $7.0 \%$ of total fat intake; milk comprises $4.2 \%$ of total fat intake; Cotton et al., 2004).

\section{Discussion}

These findings have implications for understanding both regulation of dietary behavior and how to most effectively encourage behavior change in nutrition education interventions. First, the fruits and vegetables brought to mind did not reflect nearly the diversity of types recommended by dietary guidelines. Second, those high fat foods most readily brought to mind differ in notable ways from the high fat foods that form the core of fat consumption in individuals' diets. Finally, there was a small but notable set of mistakes, seeing foods as high fat that are not (e.g., sugar, bread). 
There are, of course, limitations to this work that should be acknowledged. First, for methodological reasons we constrained individuals to considering only three specific food items per category. Given the research question of interest, this was a necessary choice-constraining individuals to those items which most easily come to mind captures those items which are most accessible, whereas allowing unlimited memory search for multiple items captures memory, not accessibility. However, although it is unlikely in day-to-day practice, individuals making decisions could theoretically consider an infinite number of potential choices for any given category. Thus, the constraints placed on participants should be considered in interpreting the results. That said, the high covariance across participants in the specific foods brought to mind suggests that a small number of foods are chronically accessible for most individuals.

A second limitation to consider is that our assessment was in an environment completely divorced from environments in which individuals commonly make decisions about food choices. Although this fact raises the possibility that different foods might be salient in an environment more directly tied to actual dietary decisions (Blake et al., 2007), from the point of view of understanding nutrition education and decision making it is quite possibly an important feature in that most nutrition education also takes place in contexts different from those in which dietary decisions are made.

These findings have implications for understanding the processes involved in understanding and responding to messages about diet and in making decisions about dietary behaviors.

Limited variability in dietary choices might be explained by the fact that our findings for all three types of foods, but particularly for fruits and vegetables, suggest that individuals' thoughts about specific fruits and vegetables are centered around a small number of particularly salient examples. Because retrieving specific food choices from memory is an important part of decision making, this potentially explains why there is limited variability in diets. In the context of fruits and vegetables, we found that legumes were rarely mentioned as a salient member of the fruit and vegetable category. This lack of salience corresponds to Guenther et al.'s (2006) finding that the consumption of legumes is at about $1 / 3$ of the recommended intake. The substantial overlap between sub-categories which are underconsumed and not frequently brought to mind suggests the potential role of category salience in dietary decision making.

Our finding that there were several mistakes in responses for high fat foods suggests a possible explanation for why individuals might not appear to follow such recommendations. If an individual is endeavoring to avoid eating high fat foods but, because of incorrect beliefs about what foods are high in fat, avoids low fat foods instead (e.g., "high carb" foods such as breads and grain products), such an individual will appear to be not following the recommendation even though he/she is attempting to consider the category of foods in making decisions.

This analysis of the role of ease of retrieval in decisions about dietary behavior suggests implications for nutrition education. First, care should be given to determine what specific food items individuals are considering when a dietitian or a public health professional is providing educational messages about a broad category of foods. To the extent that the specific foods being considered are unnecessarily limited or inappropriate, additional education can be undertaken to guide behavioral choices. Second, the findings suggest that nutrition education needs to consider ways to make additional specific food items salient and to correct misperceptions about foods. One way to do this might be to craft educational messages that address food recommendation at the level of specific food items or that address both the general categories and provide multiple, appropriate examples of ways to respond to the recommendation with specific foods.

Finally, although the relative frequency of errors in categorization is small, the implications are important. For instance, if one incorrectly believes that grains are high in fat, one may avoid these healthy foods in a mistaken attempt to avoid fatty foods. Nutrition education must communicate more effectively which foods are high versus low in fat and how to make the distinction.

\section{References}

Achterberg et al., 1994 C. Achterberg, E. McDonnell and R. Bagby, How to put the food guide pyramid into practice, Journal of the American Dietetic Association 94 (1994), pp. 1030-1035.

Bachman et al., 2008 J. L. Bachman, J. Reedy, A. F. Subar and S. M. Krebs-Smith, Sources of food group intakes among the US population, 2001-2002, Journal of the American Dietetic Association 108 (2008), pp. 804-814.

Blake et al., 2007 C. E. Blake, C. A. Bisogni, J. Sobal, C. M. Devine and M. Jastran, Classifying foods in contexts: how adults categorize foods for different eating settings, Appetite 49 (2007), pp. 500-510.

Church et al., 1985 N. J. Church, M. Laroche and J. A. Rosenblatt, Consumer brand categorization for durables with limited problem solving: an empirical test and proposed extension of the Brisoux-Laroche model, Journal of Economic Psychology 6 (1985), pp. 231-253.

Cotton et al., $2004 \rightarrow$ P. A. Cotton, A. F. Subar, J. E. Friday and A. Cook, Dietary sources of nutrients among US adults, 1994 to 1996, Journal of the American Dietetic Association 104 (2004), pp. 921-930.

Croll et al., $2001-$ J. K. Croll, D. Neumark-Sztainer and M. Story, Healthy eating: what does it mean to adolescents?, Journal of Nutrition Education 33 (2001), pp. 193-198.

Fazio et al., $2000>$ R. H. Fazio, C. J. Williams and M. C. Powell, Measuring associative strength: category-item associations and their activation from memory, Political Psychology 21 (2000), pp. 7-25.

Guenther et al., 2006 P. M. Guenther, K. W. Dodd, J. Reedy and S. M. Krebs-Smith, Most Americans eat much less than recommended amounts of fruits and vegetables, Journal of the American Dietetic Association 106 (2006), pp. 1371-1379.

Havas et al., $1995>$ S. Havas, J. Heimendinger, D. Damron, T. A. Nicklas, A. Cowan and S. A. Beresford et al., 5 A day for better health - nine community research projects to increase fruit and vegetable consumption, Public Health Reports 110 (1995), pp. 68-79.

Laroche and Brisoux, $1989 \rightarrow \mathrm{M}$. Laroche and J. E. Brisoux, Incorporating competition into consumer behavior models: the case of the attitude-intention relationship, Journal of Economic Psychology 10 (1989), pp. 343-362.

Marquart et al., 2006 L. Marquart, A.-T. Pham, L. Lautenschlager, M. Croy and J. Sobal, Beliefs about whole-grain foods by food and nutrition professionals, health club members, and special supplemental nutrition program for women, infants, and children participants/State fair attendees, Journal of the American Dietetic Association 106 (2006), pp. 1856-1860.

Mokdad et al., 2004 A. H. Mokdad, J. S. Marks, D. F. Stroup and J. L. Gerberding, Actual causes of death in the United States, 2000, Journal of the American Medical Association 291 (2004), pp. 1238-1245.

Posavac et al., 1997 S. S. Posavac, D. M. Sanbonmatsu and R. H. Fazio, Considering the best choice: effects of the salience and accessibility of alternatives on attitude-decision consistency, Journal of Personality and Social Psychology 72 (2) (1997), pp. 253-261.

Povey et al., 1998 R. Povey, M. Conner, P. Sparks, R. James and R. Shepherd, Interpretations of healthy and unhealthy eating, and implications for dietary change, Health Education Research 13 (1998), pp. 171-183.

Ross and Murphy, $1999 \rightarrow$ B. H. Ross and G. L. Murphy, Food for thought: cross-classification and category organization in a complex real-world domain, Cognitive Psychology 38 (1999), pp. 495-553.

Sobal and Cassidy, 1987 J. Sobal and C. M. Cassidy, Dieting foods: conceptualizations and explanations, Ecology of Food and Nutrition 20 (1987), pp. 89-96.

Sobal and Cassidy, 1990 J. Sobal and C. M. Cassidy, University students' perceptions of fattening and dieting foods in relationship to the 4 food groups, Nutrition Research 10 (1990), pp. 145-154.

Sobal and Cassidy, 1993 J. Sobal and C. M. Cassidy, Public beliefs about the amount of fiber in foods, Appetite 20 (1993), pp. 21-32.

United States Department of Health and Human Services, 2005 United States Department of Health Human Services, Dietary Guidelines for Americans 2005, US Government Printing Office, Washington, DC (2005). 